DOI: https://doi.org/10.34069/AI/2021.44.08.8

How to Cite:

Novikov, S.V., \& Tikhonov, G.V. (2021). Development of small innovative business in the Russian economy. Amazonia Investiga, 10(44), 84-91. https://doi.org/10.34069/AI/2021.44.08.8

\title{
Development of small innovative business in the Russian economy
}

\section{Развитие Малого Инновационного Бизнеса в Российской Экономике}

\author{
Received: July 1, $2021 \quad$ Accepted: August 20, 2021
}

\author{
Written by: \\ Sergey V. Novikov ${ }^{34}$ \\ https://www.scopus.com/authid/detail.uri?authorId=57192318711 \\ https://www.elibrary.ru/author_profile.asp?id=807011 \\ https://orcid.org/0000-0001-6921-1760 \\ Gennady V. Tikhonov ${ }^{35}$ \\ https://www.scopus.com/authid/detail.uri?authorId=57214331423 \\ https://www.elibrary.ru/author_profile.asp?id=451586 \\ https://orcid.org/0000-0001-8502-0235
}

\begin{abstract}
The article is devoted to small entrepreneurship in the scientific and technical sphere, despite the recognition of its right to state support, it has a significant difference from scientific and technical and the so-called earlier implementation activities characteristic of the period preceding economic reforms. A significant place in the article is given to the development of mathematical modeling in the system of innovative entrepreneurship in modern crisis conditions. Adaptability and flexibility are considered as the most important indicators of the efficiency of structures, their ability to ensure sustainable operation and effective innovative development of small businesses. The issues of scientific, technical and innovative activities in small business and in the public sector of the economy on the conjugation of adaptability and flexibility are considered. A number of modern techniques related to the development of mathematical modeling of the development of small enterprises in innovative activities in a crisis are analyzed. The necessity of mathematical modeling as the main factor in the implementation of financial support for small business in innovation, for which conventional methods are unacceptable, has been substantiated. The proposed approach should be considered as a guideline when assessing the mechanism for allocating funds from the budget for the development of small business in innovation.
\end{abstract}

\section{Аннотация}

Статья посвящена малому предпринимательству в научно-технической сфере, несмотря на признание его права на государственную поддержку, имеет существенное отличие от научнотехнической и так называемой ранее внедренческой деятельности, характерных для периода, предшествовавшего экономическим реформам. Значительное место в статье уделено разработке математического моделирования в системе инновационного предпринимательства в современных кризисных условиях. Адаптивность и гибкость рассматриваются в качестве наиболее важных показателей эффективности структур, их способности обеспечивать устойчивое функционирование и эффективное инновационное развитие малых предприятий. Рассмотрены вопросы научно-технической и инновационной деятельности как в малом предпринимательстве, так и в государственном секторе экономики о сопряжении адаптивности и гибкости. Проанализирован ряд современных методик, связанных с разработкой математического моделирования развития малых предприятий в инновационной деятельности в условиях кризиса. Обоснована необходимость проведения математического моделирования как основного фактора реализации финансовой поддержки малого

\footnotetext{
${ }^{34} \mathrm{PhD}$ in Econimic Sciences, Associate Professor, Moscow Aviation Institute (National Research University), Moscow, Russia

${ }^{35} \mathrm{PhD}$ in Econimic Sciences, Associate Professor, Moscow Aviation Institute (National Research University), Moscow, Russia.
} 


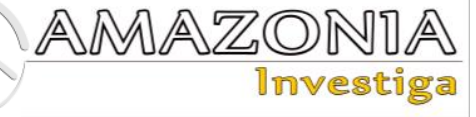

Keywords: innovation, entrepreneurship, adaptability, infrastructure, R\&D, regions, technology, mathematical modeling, corporation, budget funds. предпринимательства в инновации, для которого обычные методики неприемлемы. Предложенный подход должен рассматриваться в качестве ориентира при оценке механизма распределения средств из бюджета на развитие малого бизнеса в инновации.

Ключевые слова: инновация, предпринимательство, адаптивность, инфраструктура, НИОКР, регионы, технология, математическое моделирование, корпорация, бюджетные средства.

consumer demand in the market and its saturation with a wide range of goods; it allows taking into account local characteristics and traditions of the population of a given region when organizing production and also creates additional jobs.

Small and medium-sized enterprises in foreign countries are actively involved in the implementation of scientific and technical programs, as well as in inter-firm alliances.

In a natural course of events, small innovative business was brought to the forefront of scientific and technological progress, and where the risk and uncertainty of results were maximum. However, even in this case, consuming only 2$5 \%$ of the total expenditure on $\mathrm{R} \& \mathrm{D}$, small business in the USA and Western Europe created and still creates up to $50 \%$ of the largest innovations sold on the world market (Damyanova, 2013; Agapie et al., 2018).

In Russia, small innovative business did not become widespread, since it did not fit into the administrative system of managing the national economy.

Small business does not set the goal of solving federal problems, but directs its efforts and resources to problems of a local and private nature, which are "invisible" for federal government bodies.

Despite the existing significant difference, scientific, technical and innovative activities in small business and in public sector of the economy are closely related, they complement and enrich each other (Balashevich and Bykova, 2012; Burdina et al., 2020).

State support for scientific, technical and innovative activities today provides for 
assistance in solving this issue by providing subsidies and subventions for small and mediumsized businesses in innovative activities.

Regional and municipal authorities are also concerned about the problem of attracting investment in innovative projects.

For the work of today's business representatives in the field of innovative development, state support for scientific, technical and innovative activities is insufficient. It is necessary to form new approaches and methods that would support innovative small businesses. The purpose of this article is the proposed mathematical modeling of the implementation of financial support for small businesses in innovation, for which conventional methods are unacceptable.

\section{Theoretical Basis}

Scientific and technical developments and innovations act as an intermediate result of the scientific and production cycle and, as they are practically applied, they turn into scientific and technical innovations: the final result.
Research and production cycle is the process of creating, mastering and disseminating a specific innovation. The cycle of innovations is closed, since production is not only the arena for the application of scientific knowledge, but also the most important source of information for their development.

Scientific and technical developments and inventions are the application of new knowledge for the purpose of its practical application, and scientific and technical innovations are the materialization of new ideas and knowledge, discoveries, inventions and scientific and technical developments in the production process with the aim of their commercial implementation to meet certain consumer needs. The indispensable properties of innovation are scientific and technical novelty and industrial applicability.

Based on the area in which changes are being made, it is possible to distinguish product, technological and organizational and managerial innovations (Figure 1).

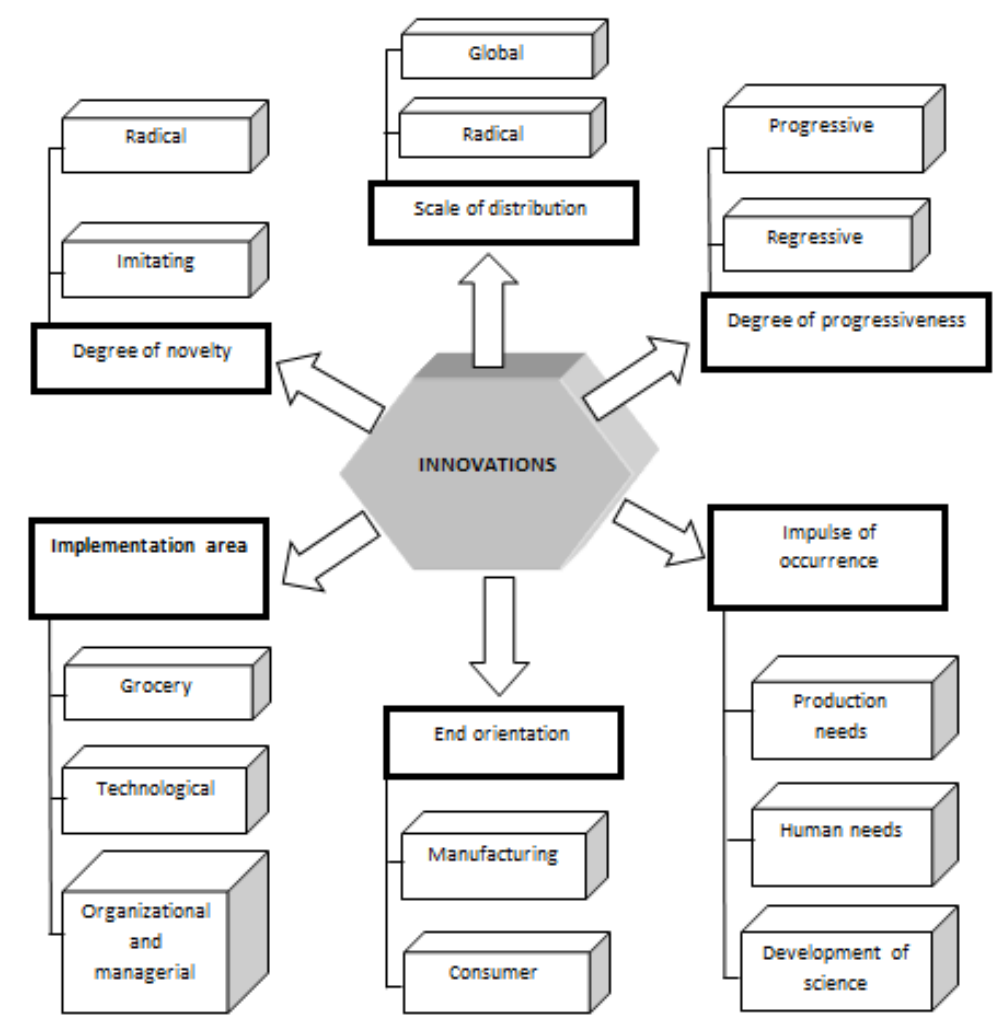

Figure 1. Areas of implementation change innovation (Source: authors)

Product innovation is associated with changes made to products manufactuder in the field of material production and consumed as means of production or consumer goods. Technological innovations involve changes in technology (methods) of creation, production and 


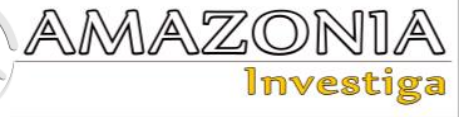

consumption of manufactured or new products. Organizational and managerial ones are associated with the introduction of new methods of organizing any systems and managing them.

In terms of the degree of novelty, radical and imitation innovations are distinguished. These concepts are associated with the theory of cyclical development and imply innovations of a revolutionary type, implementing large inventions or their clusters, and of an evolutionary type that arise within existing technological systems (Valdaitsev, 2013).

\section{Methodology}

This is especially evident today: most of the current small business entities and small firms that, according to the legislation, cannot be classified as these entities, was formed in the depths of large and medium-sized scientific organizations, higher educational institutions and industrial enterprises. Having gained legal independence, they often do not interrupt the connecting threads with their "parents" and in many cases are actually their subsidiaries (Burdina and Bondarenko, 2020).

In turn, large and medium-sized organizations and enterprises, due to this process, received real opportunities for the practical implementation (often in rather unexpected areas and spheres of application) of those of their scientific and technical developments and groundwork that were not previously in demand and were without movement.

Thus, in the context of the transition to a market economy, the development of scientific, technical and innovative activities, as one of the priority areas of small business, is an important strategic tool of the state to overcome the crisis and stabilize the economy.

It is very important for the regions of the Russian Federation, since it is connected with the objective needs of solving their economic, environmental and social problems and shifting the center of gravity on many problems of socioeconomic development to the localities, such as providing the population with food, health care, housing and communal services, etc.

Due to limited resources, the solution of these problems is possible only under the condition of maximum involvement of all (state and nonstate) scientific, technical and innovation potentials available in the regions of Russia. It makes it necessary to unite and coordinate the efforts of federal and territorial authorities with a clear division of their functions and responsibilities.

For the federal level of government, the central task is to preserve the state's resource support for the core of fundamental science, to involve it in solving global problems of scientific and technological development of the country, to ensure national technological security in the future and to preserve a single scientific, technical and information space throughout Russia and its international scientific connections. For the regional level of management, the priority is the task of forming a local order for scientific, technical and innovative activities and creating conditions for the implementation of the results obtained from it through the mechanisms of a market economy (Pinkovetskaia et al., 2020a; Pinkovetskaia et al., 2020b).

The development of scientific, technical and innovative activities in Russian regions and the organizational elements of its infrastructure that have developed in them have serious shortcomings.

For the most part, this activity is still focused mainly on large and medium-sized scientific organizations, higher educational institutions and industrial enterprises. The share of small businesses in its implementation is still clearly insufficient.

State support for scientific, technical and innovative activities is of a departmental nature, and at present, its purposeful, mutually agreed implementation in the interests of supporting small business has not yet been achieved.

In many regions, organizational and economic conditions have not yet been created that would favor the implementation of scientific, technical and innovative activities and stimulate its development in the field of small business. The formed infrastructure of scientific, technical and innovation activities is still not complex in nature, since its organizational elements do not cover a significant part of those functions, the implementation of which determines success in a market economy (Dmitriev and Novikov, 2021).

The organizational elements of the infrastructure are distributed very unevenly across the territory of Russia, and their total number is clearly insufficient. They are almost completely absent in more than a quarter of the constituent entities of the Federation, and in the overwhelming 
majority of republics, territories, regions, autonomous formations they exist in the form of one, maximum two or three separate specialized organizations.

The material and technical base of the organizational elements of the infrastructure, especially in terms of production areas and equipment that could be provided for R\&D and the implementation of innovative projects, is usually poorly developed and does not meet modern requirements.

Both at the regional and federal levels of government there is no clear picture and precise knowledge about the quality of the organizational elements of the infrastructure, their systematic assessment and analysis are not carried out (Semenov, 2003).

The proposed mathematical modeling of the implementation of financial support for small businesses in innovation, for which the usual methods are unacceptable (Semyonov and Pecherskikh, 2011).

In the business world, mathematical models provide optimal budget allocation among small businesses that are focused on innovation, using fast programming. Fast programming method is based on the principles of optimal allocation of funds from the budget.

The proposed mathematical model will allow small business to develop effectively.

Support of small businesses by the state through their financing is one of the important instruments of state influence on the system as a whole. Small enterprises are an echelon of economic dynamics and one of the main tasks of innovative entrepreneurship is financial assistance to small enterprises specializing in innovation (Tikhonov and Grachev, 2013).

One of the types of financial assistance can be tax incentives for small businesses operating in innovation:

- amount of the monthly loan repayment (principal debt) is expensed;

- $\quad$ value added tax (20\% from sale of services);

- $\quad$ property tax (2.2\% of property value).

In connection with the limited budgetary financing of innovation centers, the question of the efficiency of allocation of budgetary funds to regions and further to centers and small enterprises constantly arises (Tikhonov, 2015).
To optimize the model under consideration, a mathematical model of financial support for new economic structures and small enterprises operating in innovation was developed (Tebetkin, 2013). The versatility of the approach used allows, in principle, to apply it to improve the efficiency of support for small businesses and in other socially significant sectors. We consider the basic principles of constructing a mathematical model of financial support for small business.

The problem of optimal distribution of budgetary funds between small businesses can be solved by the method of dynamic programming. The fast programming method is based on the principle of the maximum solution regardless of the initial state of the value of the parameter $X 1$ and also the solution of the value of $U 1$, provided that each solution subsequent to $U 1$ must be maximum in comparison with the value of $X 2$ resulting from the solution of the value of $U 2$.

This principle is valid for a wide range of systems, the future behavior of which is completely determined by their state in the present.

The mathematical notation of the optimality principle leads to a certain class of functional equations, which, in particular, can have the following form corresponding to the problem under consideration:

$$
\begin{gathered}
f(x)=\max [g(X n)+f(X-X n)] \\
0<X n<X
\end{gathered}
$$

where $X$ is the amount of resource to be allocated; $\mathrm{f}(X)$ and $g(X)$ are the nonlinear utility functions; $X n$ is the solution of the functional equation for a fixed $X$.

In the general multidimensional case, equations of type (1) describe the problem of efficient use of limited amounts of resources of various types. The problem under consideration is reduced to the simplest one-dimensional case yet: efficient use of one resource (total amount of financing $F$ ), distributed between $n$ small business. If $F 1$ is the amount of funding allocated for the first small business, then the function $D 1(F 1)$ characterizes the corresponding level of educational, innovative or scientific and technical activities. Denoting by $D(F 1, F 2 \ldots \ldots . . F n)$ the total level of activity, which is obtained for a certain distribution of funding $(F 1, F 2 \ldots \ldots . F n)$, the distribution problem can be reduced to 


\section{AMAZOND周 \\ ปnvestig.}

determining the maximum of functions $n$ variables.

$$
\begin{gathered}
D(F 1, F 2 \ldots \ldots . . F n)=D 1(F 1)+D 2(F 2)+\ldots \ldots . . \\
+D n(F n)
\end{gathered}
$$

with limitations

$$
F 1+F 2+\ldots .+F n=F, F i \geq 0 .
$$

It follows from (2) that the function D (F1, F2 $\mathrm{Fn})$ as an optimality criterion has the following two properties:

A. The level of activity of each small business does not depend on the amount of funding from other small business;

B. The general level of activity is equal to the sum of the levels of activity of all small businesses.

When using the method of functional equations to maximize (2), the problem seems to be immersed in a certain family of budget allocation processes. In this case, instead of considering one problem with a given amount of funding and a fixed number of small businesses, a whole family of such problems is considered, in which F can take any positive, and $\mathrm{n}$ can take any whole problems.

The distribution of budgetary funds, which at first is perceived as a statistical process, in dynamic programming is artificially deployed in time. First, a certain amount of funds is allocated to the $i$-th small business, at the next moment of time $(i+1)$-th, etc. This introduces a dynamic distribution process.

Analytically considering that the maximum of the function $D(F 1, F 2 \ldots \ldots . . F n)$ in the indicated region depends on $F$ and $n$, it is possible to make this dependence explicit, setting $F \geq 0$, as follows:

$$
f n(F)=\max D(F 1, F 2 \ldots \ldots . . F \mathrm{n}),
$$

where $\{F i\}$ are the sets of $n$ elements belonging to the set given by the constraints $F i \geq 0$ and $F 1+F 2+\ldots . .+F n=F$.

Function $f n(F)$ expresses the maximum result obtained from the optimal distribution of funds $F$ about $n$ small business. For two special cases, the elements of the sequence $\{f n(F)\}$ have a simpler form.

A. If $D i(0)=0$ for any $i$, then, obviously, there is the condition:

$$
f n(0)=0, \mathrm{n}=1,2 \ldots
$$

The considered simplification can in any case be provided by subtracting from the function $D i$ of initial values $D i(0)$.

B. For any nonnegative $\mathrm{F}$, there is the quite obvious condition:

$$
f i(F)=\operatorname{Di}(F) .
$$

Recurrence relation connecting $f n(F)$ and $f n-1(F)$ for arbitrary $n$ and $F$ can be obtained from the following considerations. We denote by $F n(0 \leq$ $F n \leq F)$ the amount of funds allocated for the $n$ th small business. In this case, regardless of the value $F n$, remaining funds $F-F n$ should be used in such a way as to obtain the maximum level of activity of the remaining (n-1) small business. Since this maximum level from the distribution of funds $F$ - $F n$ of $(n-1)$ small business, there is $f n$ $1(F-F n)$, the selection $F n$ for $n$-th small business leads to an overall result equal to

$$
D n(F n)+f n-1(F-F n) .
$$

for the model $n$ small business.

Therefore, the optimal choice of $F n$ is that it maximizes function (6). The main functional equation for the distribution of funds is obtained in the following form:

$$
\begin{gathered}
f n(F)=\max [D n(F n)+f n-1(F-F n)], \\
0 \leq F n \leq F,
\end{gathered}
$$

where $n=2,3, \ldots \ldots, F>>$, and $f i(F)=D \mathrm{i}(F)$.

\section{Results}

If we consider the problem of allocating budget funds as a problem of maximizing a function of $n$ variables, then relation (7) allows transferring this $n$-dimensional extreme problem to solving $n$ one-dimensional extreme problems. The dynamic programming method, in contrast to the classical method for solving extreme problems, allows one to find extreme values also in those cases when the optimum is on the boundary of the region on which the function under study is specified.

Since the implementation of the dynamic programming method naturally breaks down into a preliminary stage of cumbersome calculations and a repeated optimization stage for various amounts of funding, the above algorithm consists of two corresponding parts, and the second stage 
is presented in the form of procedures for direct or automated enumeration of options. In addition, the presented program makes it possible to apply the dynamic programming method not only based on activity functions, but also on activity functions.

In general, the results obtained correspond to the limiting possibilities of budgetary financing of research works (in the case of management by activity) and should be considered as a standard in assessing the real mechanisms of allocation of budgetary funds (in management by activity).

\section{Discussion}

Russia should develop its own strategy for enhancing innovation, which would rely on the country's intellectual potential and scientific and technical resources. Analysis of innovation strategies shows that the "transfer" strategy can be implemented only in the areas where there is no own scientific and technical potential, or is available on a limited scale, since, on the one hand, the acquisition of know-how and licenses requires significant financial costs, and on the other hand, the know-how and licenses for the production of high-performance products or high technologies will not be sold to another country, which has significant scientific, technical and production potential, in order to exclude competition.

Elements of the "borrowing" strategy can be used more actively, in which joint ventures are organized to produce competitive products in Russia with their sale in Russia and on the foreign market using those economic niches in which the joint production partner already sells such products. Such processes have already begun in the field of joint (or at the order of individual Western firms) production of elements of electronic equipment, assembly of complex household electronic equipment. These industries will allow, on the one hand, maintaining the existing production potential, providing employment and further developing their own innovative projects. With this strategy, the development of the small business sector in the innovation sphere will play a great role, since one of the advantages of small businesses is their functioning in large industries to ensure a quick changeover of technologies for the production of products required for the main production.

The policy of "building up" small business in innovation in the state can also be implemented during the heyday of the types of products of the machine-building complex, in which there is scientific progress, technical and economic potential (Novikov, 2019).

In the Russian economy, innovation policy should include all components of the market. In conditions of limited financial resources, it must be based on implementation in a limited environment, which is a very memorable innovative project, which is being implemented there by a promising chime. In this direction, it is necessary to focus on the primacy of Russian science in the field of technical technology, the threshold values for the implementation time should be within 2-5 years (Amorós et al., 2019).

The need to provide a guarantor of state funding is, on the one hand, for the government to issue an order on a competitive basis, but at the same time it is the participation of investors on the other hand.

\section{Conclusion}

Small organizations, small capitals quickly react to changes in the market, to its demand, to its supply. Lack of "bureaucracy" in small business, this sector knows how to take risks in innovations, which for large enterprises is risky and not very promising. With all this, small businesses have contacts with customers for the sale of products and they are also informed about changes in market demand. In addition, the specificity of implementation activities implies a lot of labor-intensive manual operations, suspension of production facilities, underemployment of staff, a combination of highly skilled and unskilled labor, i.e. what small firms are more suited to. Mobility and flexibility of the transition to innovations, small management staff, simple organizational ties, high qualification of staff, maximum concentration on solving the problem, high susceptibility to fundamental innovations, use of disadvantageous areas of production for large enterprises and taking into account local conditions: all these constitute the advantages of an infrastructure element - "Innovative technological center" and allows it to often overtake more powerful competitors in scientific and technical competition. Such centers act as pioneers of market niches, which are then filled by large corporations, and reduce the risk of scientific and technical research and the production of a new product.

\section{Bibliographic references}

Agapie, A., Vizitiu, C., Cristache, S. E., Năstase, M., Crăciun, L., and Molănescu, A. G. 


\section{AMAZONLA \\ ]กvestigga}

(2018). Analysis of corporate entrepreneurship in public R\&D institutions. Sustainability, 10(7), 2297.

Amorós, J. E., Poblete, C., and Mandakovic, V. (2019). R\&D transfer, policy and innovative ambitious entrepreneurship: evidence from Latin American countries. The Journal of Technology Transfer, 44(5), 1396-1415.

Balashevich, M. I., and Bykova, T. P. (2012). Economics and Small Business Organization. Minsk: Belarusian State Economic University.

Burdina, A. A., and Bondarenko, A. V. (2020). Assessing the Strategic Efficiency of Aviation Projects. Russian Engineering Research, 40(5), 439-441

Burdina, A. A., Moskvicheva, N. V., and Burdin, S. S. (2020). Modernization of High-Tech Products with Strategic-Risk Assessment. Russian Engineering Research, 40(12), 115-1117.

Damyanova, L. T. (2013). The experience of European countries in creating a new type of universities. Creative economy, 12(84), 95-101.

Dmitriev, O. N., and Novikov, S. V. (2021). Simulation in Managing an Enterprise's Stock of Equipment and Parts. Russian Engineering Research, 41(1), 76-78.

Dmitriev, O., \& Novikov, S. (2019). Concept of organization and functioning of integrated electronic infosphere of reporting on R \& D works' results. Amazonia Investiga, 8(21), 87-95. Retrieved from https://amazoniainvestiga.info/index.php/am azonia/article/view/50hp/amazonia/article/vi ew/79

Novikov, S. V. (2019). Problems of the Russian economy integration in the sphere of hightech global space. TEM Journal, 8(1), 207-210.

Novikov, S., Komarova, N., \& Dadyan, K. (2019). Development of a motivation system and supporting the success of the internal and external interactions of the network project group. Amazonia Investiga, 8(20), 200-209. Retrieved from https://amazoniainvestiga.info/index.p
Pinkovetskaia, I. S., Arbeláez-Campillo, D. F., Rojas-Bahamón, M. J., and Veas Iniesta, D. S. (2020a). Motivation of new entrepreneurs in modern economies. Amazonia Investiga, 9(29), 368-373.

https://amazoniainvestiga.info/index.php/am azonia/article/view/1403

Pinkovetskaia, I., Arbeláez-Campillo, D., Rojas-Bahamón, M., Novikov, S., and Veas Iniesta, D. (2020b). Social values of entrepreneurship in modern countries. Amazonia Investiga, 9(28), 6-13. https://amazoniainvestiga.info/index.php/am azonia/article/view/1276

Schot, J., and Steinmueller, W. E. (2018). Three frames for innovation policy: R\&D, systems of innovation and transformative change. Research Policy, 47(9), 1554-1567.

Semenov, V. P. (2003). Problems of managing the innovation and investment process. Innovations, 8,48

Semyonov, A. G., and Pecherskikh, I. A. (2011). Mathematical models in economics: textbook. Kemerovo: Kemerovo Technological Institute of Food Industry.

Shamina, L. K. (2008). Theoretical aspects of the functioning of innovation processes. St. Petersburg: Science.

Tebetkin, A. V. (2013). Innovation management: Textbook for bachelors. Moscow: Yurayt.

Tikhonov, G. V. (2015). Basic approaches to small business lending methods. Bulletin of the Moscow Institute of Electronics and Mathematics, 202-206.

Tikhonov, G. V. (2019). Operational Production Management Model of Competitive Products in Mechanical Engineering. TEM Journal, 8(4), 1137-1142.

Tikhonov, G. V., and Grachev, N. N. (2013). Methodology for lending to microenterprises as an echelon of economic dynamics in modern conditions. Innovative information technology, 4(2), 281-284.

Tslaf, V. M. (2012). Business of the 21st century: predictable trends. Fundamentals of Economics, Management and Law, 2, 84-91.

Valdaitsev, S. V. (2013). Small innovative entrepreneurship. Moscow: Prospect. 